
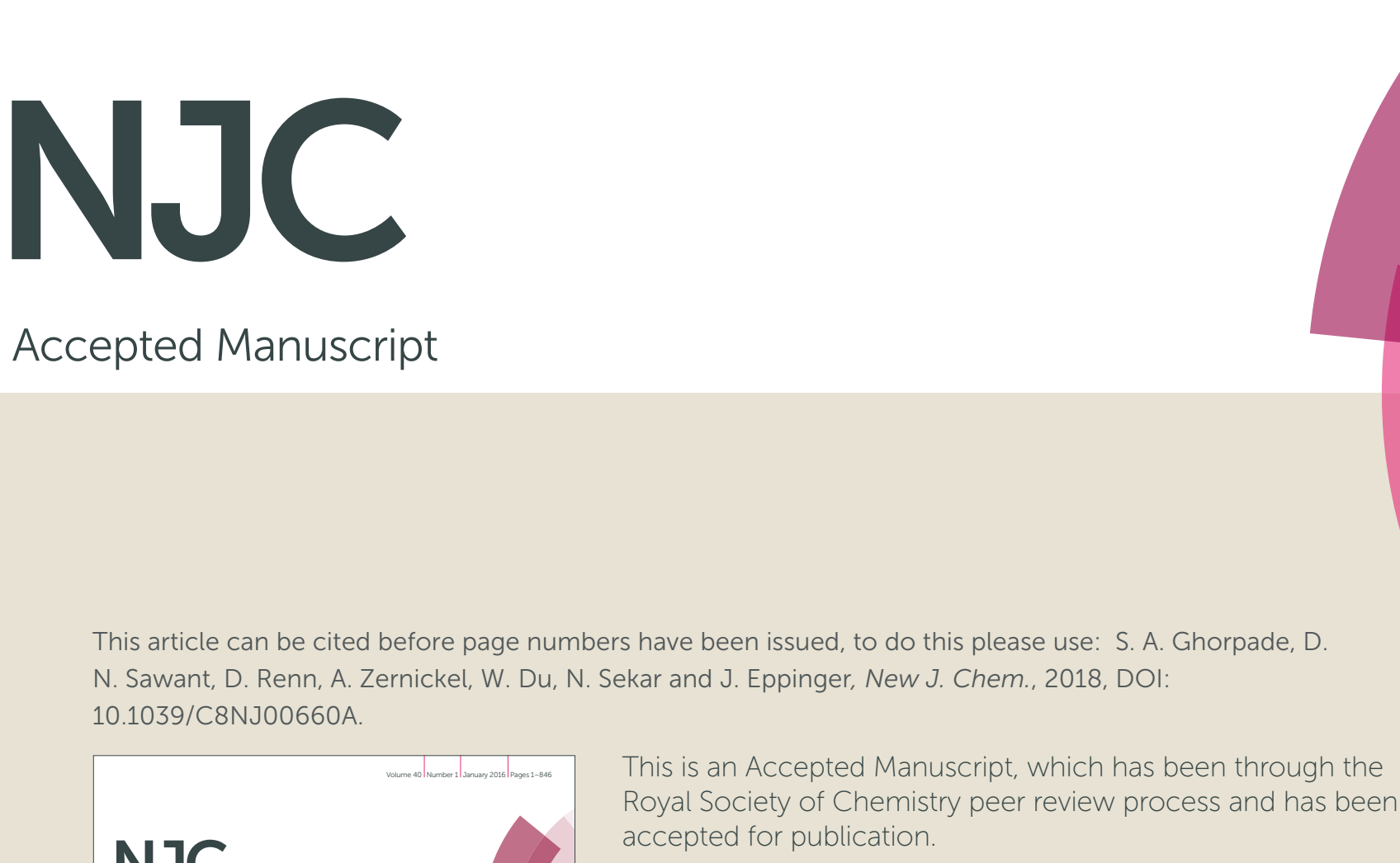

This article can be cited before page numbers have been issued, to do this please use: S. A. Ghorpade, D. N. Sawant, D. Renn, A. Zernickel, W. Du, N. Sekar and J. Eppinger, New J. Chem., 2018, DOI:

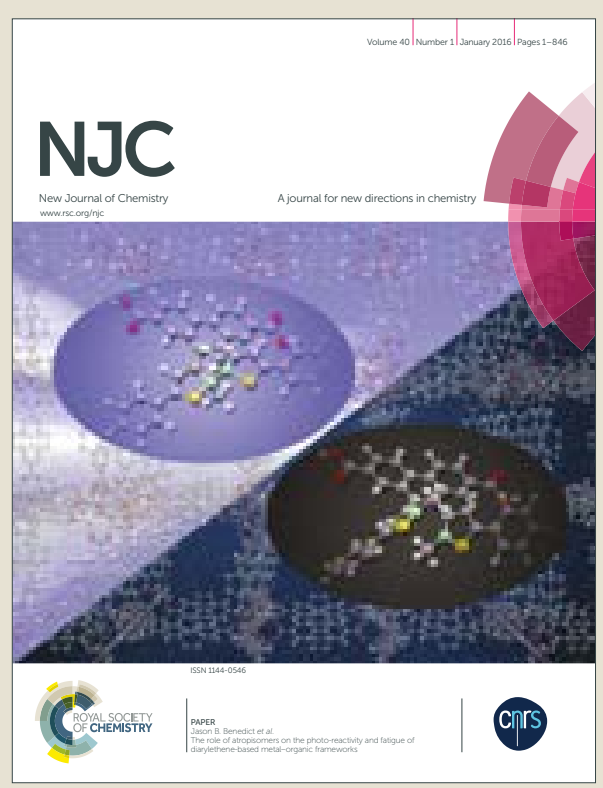

This is an Accepted Manuscript, which has been through the Royal Society of Chemistry peer review process and has been accepted for publication.

Accepted Manuscripts are published online shortly after acceptance, before technical editing, formatting and proof reading. Using this free service, authors can make their results available to the community, in citable form, before we publish the edited article. We will replace this Accepted Manuscript with the edited and formatted Advance Article as soon as it is available.

You can find more information about Accepted Manuscripts in the author guidelines.

Please note that technical editing may introduce minor changes to the text and/or graphics, which may alter content. The journal's standard Terms \& Conditions and the ethical guidelines, outlined in our author and reviewer resource centre, still apply. In no event shall the Royal Society of Chemistry be held responsible for any errors or omissions in this Accepted Manuscript or any consequences arising from the use of any information it contains. 


\title{
ARTICLE
}

Received 00th January 20xx, Accepted 00th January 20xx

DOI: $10.1039 / x 0 x \times 00000 x$

www.rsc.org/

\section{Aqueous protocol for allylic arylation of cinnamyl acetates with sodium tetraphenylborate using Bedford-type palladacycle catalyst}

\author{
Seema Arun Ghorpade ${ }^{a, b}$, Dinesh Nanaji Sawant ${ }^{* a}$, Dominik Renn $^{a}$, Anna Zernickel $^{a}$, Weiyuan Du ${ }^{a}$, \\ Nagaiyan Sekar*b and Jörg Eppinger*a
}

\begin{abstract}
Allylic arylation of cinnamyl acetates with sodium tetraphenylborate using $0.002 \mathrm{~mol} \%$ of Bedford-type palladacycle catalyst is described. The developed methodology is applicable for wide range of cinnamyl acetates furnishing excellent yields up to $93 \%$. Notably all reactions proceed smoothly under mild reaction conditions in water under air atmosphere.
\end{abstract}

\section{Introduction}

The palladium catalyzed allylic nucleophilic substitution reactions popularly known as Tsuji-Trost reactions, ${ }^{1}$ have wide applications in the synthesis of agrochemicals, natural products and pharmaceuticals. ${ }^{2}$ Depending on the type of nucleophiles involved in the Tsuji-Trost reaction they are categorized as allylic amination, ${ }^{3}$ allylic alkylation, ${ }^{4}$ allylic arylation, ${ }^{5} \mathrm{O}$-allylation ${ }^{6}$ etc. Therefore, Tsuji Trost reactions are versatile tool to introduce internal alkene into industrially important compounds with various functionalities. Notably 1,3-Diarylpropene derivatives are integral part of many natural products and biologically active compounds such as obtusastyrene and obtustyrene. ${ }^{5 b}$ Previously synthesis of 1,3 Diarylpropene derivatives was reported using Heck-type allylic $\mathrm{C}-\mathrm{H}$ arylation with arylboronic acids which resulted in the mixture of the double-bond-migrated isomers. ${ }^{7}$ Instead 1,3Diarylpropene derivatives are easily synthesized using palladium-catalyzed Tsuji Trost type allylic arylation in single step. Therefore, there is growing interest in palladium catalyzed allylic arylation reactions using aryl boron reagents because of their wide applications. ${ }^{8}$ In most of the reports sodium tetraphenylborate $\left(\mathrm{NaBPh}_{4}\right)$ and its derivatives are reagents of choice ${ }^{9}$ due to their high reactivity as compared to the corresponding aryl boronic acid derivatives ${ }^{10}$. In this regard Uozumi et al. recently reported several effective catalysts at parts per million to parts per billion levels catalyst loading such as self-assembled poly(imidazole-palladium)

\footnotetext{
a. King Abdullah University of Science and Technology, Division of Physical Sciences \& Engineering and KAUST Catalysis Center (KCC), Thuwal 23955-6900, Saudi Arabia.

E-mail: jorg.eppinger@kaust.edu.sa,dinesh1.sawant@gmail.com

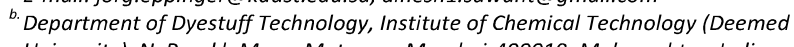
University), N. Parekh Marg, Matunga, Mumbai-400019, Maharashtra, India. E-mail: n.sekar@ictmumbai.edu.in (N.S.)

Electronic Supplementary Information (ESI) available: [details of any supplementary information available should be included here]. See
} DOI: $10.1039 / \times 0 \times x 00000 x$ composite and palladium NNC-pincer complex for allylic arylation of allylic acetates with sodium tetraarylborates. ${ }^{11}$ However, despite of impressive improvement the use of toxic organic solvent methanol or isopropanol, longer reaction time, and requirement of inert conditions are major drawbacks. Nevertheless, the reported methods leave room for further development to more effective and greener protocols. Ideally allylic arylation using lower catalyst loading, mild reaction conditions under air atmosphere and water as solvent is the more demanding approach in respect to industrial applications. ${ }^{12}$ It is noteworthy to mention that water is the solvent of choice for many industrial applications, not only because it is an environmentally benign solvent but also because water is safe to handle, readily available and an inexpensive universal solvent. In this regard, we believe that Bedford type catalysts have good potential for developing an effective aqueous protocol for allylic arylation. ${ }^{13}$ Recently our group has developed a new Bedford-type palladacycle catalyst (Scheme 1) and explored for aqueous Suzuki coupling as well as for borylation reactions. ${ }^{14}$ Therefore, in continuation with our longtime interest in developing catalytic protocols for wide applications, ${ }^{15}$ herein we report our studies on the application of our Bedford-type palladacycle catalyst (Cat. A, Scheme 1) for aqueous Tsuji Trost type allylic arylation of cinnamyl acetates with sodium tetraphenylborates as an arylating agent.

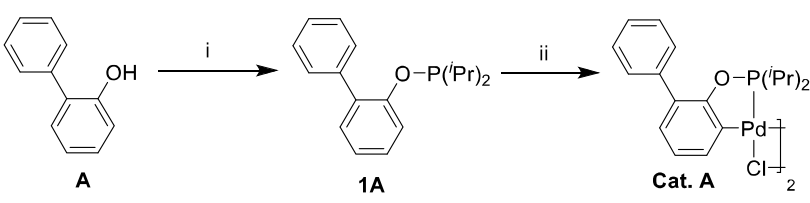

Scheme 1 Reaction Conditions: (i) $\mathrm{NEt}_{3}, \mathrm{ClPiPr}_{2}$, toluene, reflux, $16 \mathrm{~h}$. (ii) $\mathrm{PdCl}_{2}$, toluene, reflux, $16 \mathrm{~h}^{14}$ 


\section{Result and Discussion}

First, we investigated the reaction of cinnamyl acetate (1a) with sodium tetraphenylborate (2a) in the presence of sodium carbonate $\left(\mathrm{Na}_{2} \mathrm{CO}_{3}\right)$ with our Bedford-type palladacycle catalyst (Cat. A) in water and under inert conditions.

Table 1. Test Experiments ${ }^{a}$

\begin{tabular}{|c|c|c|c|c|}
\hline \multirow[b]{2}{*}{1} & \multirow{2}{*}{$\mathrm{OAC}+\stackrel{\oplus}{\mathrm{Na}} \stackrel{\ominus}{\ominus}$} & \multirow{2}{*}{$2 a$} & $\begin{array}{l}\text { Cat. A }(5 \mathrm{~mol} \%) \\
\mathrm{Na}_{2} \mathrm{CO}_{3}(0.2 \mathrm{mmol})\end{array}$ & \multirow{2}{*}{$3 a$} \\
\hline & & & $\begin{array}{l}\text { Water }(5 \mathrm{~mL}) \\
30^{\circ} \mathrm{C}, 16 \mathrm{~h}\end{array}$ & \\
\hline Entry & Cat. A & $\mathrm{Na}_{2} \mathrm{CO}_{3}$ & Argon & $3 a$ yield ${ }^{b}[\%]$ \\
\hline 1 & + & + & + & 98 \\
\hline 2 & & + & + & 0 \\
\hline 3 & + & & + & 98 \\
\hline 4 & + & & & 98 \\
\hline
\end{tabular}

a Reaction Conditions: 1a $(0 . \overline{20} \mathrm{mmol}), 2 \mathrm{a}(0.40 \mathrm{mmol})$, Cat. A $(5 \mathrm{~mol} \%)$ $\mathrm{Na}_{2} \mathrm{CO}_{3}(0.20 \mathrm{mmol})$, Water, $(5 \mathrm{~mL}), 30{ }^{\circ} \mathrm{C}, 16 \mathrm{~h} .{ }^{\mathrm{b}} \mathrm{GC}$ Yield

Interestingly, in our first attempt almost $98 \%$ yield of 3a were obtained (Table 1, entry 1). Encouraged by this result a set of test reactions were carried out, to check the role of catalyst, base and inert conditions (Table 1). It was observed that in the absence of Cat. A, the reaction did not proceed, which confirms the important role of Cat. A (Table 1, entry 2). However, in the absence of base still $98 \%$ product 3a was obtained and proofs that base has no influence on the reaction outcome (Table 1, entry 3). Succeeding, we carried out reaction in air atmosphere; interestingly almost $98 \%$ of $3 a$ were obtained (Table 1, entry 4), therefore, all the next experiments were performed in air atmosphere. Additionally,

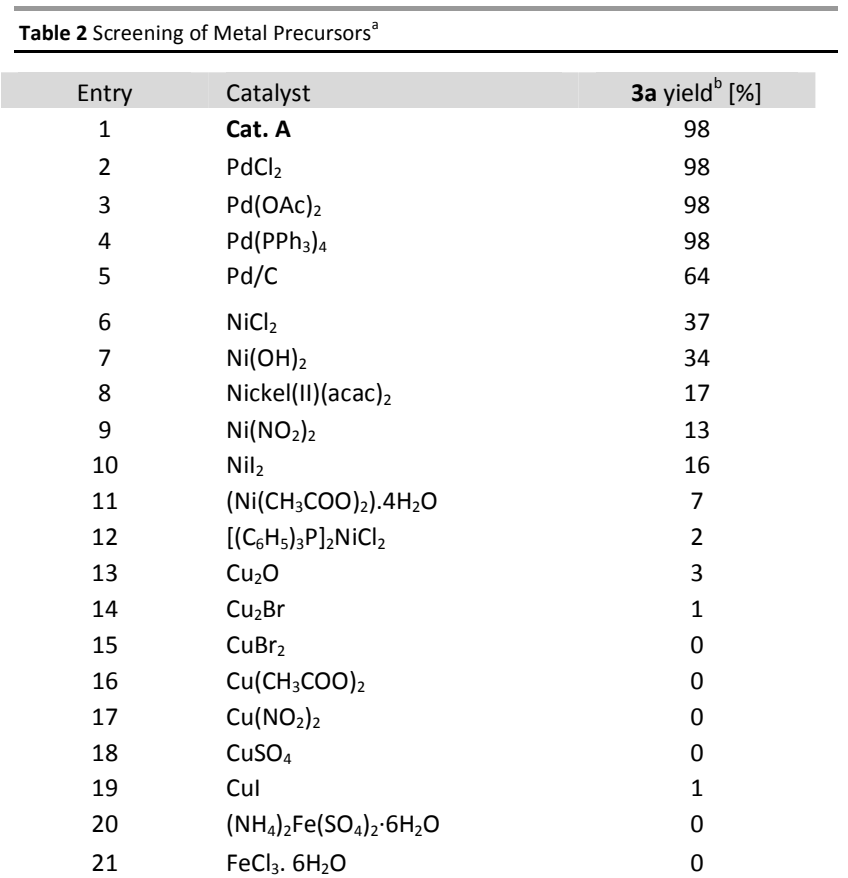

${ }^{a}$ Reaction Conditions: 1a $(0.20 \mathrm{mmol}), 2 \mathrm{2a}(0.40 \mathrm{mmol})$, catalyst $(5 \mathrm{~mol} \%)$, water (2 mL), $30{ }^{\circ} \mathrm{C}, 16 \mathrm{~h} .{ }^{\mathrm{b}} \mathrm{GC}$ yield. the effects of solvent volume confirm that $2 \mathrm{~mL}$ of water is sufficient to achieve higher yield of $\mathbf{3 a}$ (See SI, Table 1). In order to compare the catalyst activity of Cat. A with other catalysts, we screened various commercially available transition metal salts and complexes of palladium, nickel, copper and iron (Table 2). It was observed that most of the palladium salts and complexes are good catalyst for allylic arylation and almost $98 \%$ of 3 a were obtained (Table 2, entries 1-5). Interestingly, with $\mathrm{NiCl}_{2}$ and $\mathrm{Ni}(\mathrm{OH})_{2}$ as catalyst moderate yields of $3 a$ up to $37 \%$ and $34 \%$ respectively were obtained (Table 2, entries 6 and 7) while use of other nickel salts and complexes resulted in lower yield of product 3a (Table 2, entries 8-12). In addition, reactions performed with copper and iron catalysts were not successful (Table 2, entries 13-21). Therefore, among the screened catalysts, palladium catalysts were identified to be the best catalysts for allylic arylation under aqueous conditions. Subsequently among the screened catalysts it is important to select the best palladium catalyst having high catalytic activity at lower catalyst loading. Thus, we checked the lowest possible catalyst loading of our Bedford-type palladacycle catalyst (Cat. A). This study is done by systematic decreasing of Cat. A loading from $5 \mathrm{~mol} \%$ to $0.0002 \mathrm{~mol} \%$ and its effect on the yield of $3 a$ were studied (Table 3). To select the lowest effective catalyst loading for achieving higher yields reactions were stopped after 8 hours. It was observed that with use of up to $0.008 \mathrm{~mol} \%$ of Cat. A there is no significant decrease in yield of $\mathbf{3 a}$ and almost $98 \%$ yield was obtained (Table 3, entries 1-9), while lowering the catalyst loading further results in decrease in the yield of $\mathbf{3 a}$ (Table 3, entries 10-14).

\begin{tabular}{|c|c|c|c|}
\hline Entry & Catalyst & Catalyst (mol \%) & $3 a$ yield ${ }^{b}[\%]$ \\
\hline 1 & Cat. A & 2 & 98 \\
\hline 2 & Cat. A & 1 & 98 \\
\hline 3 & Cat. A & 0.5 & 98 \\
\hline 4 & Cat. A & 0.25 & 98 \\
\hline 5 & Cat. A & 0.13 & 98 \\
\hline 6 & Cat. A & 0.063 & 98 \\
\hline 7 & Cat. A & 0.031 & 98 \\
\hline 8 & Cat. A & 0.016 & 98 \\
\hline 9 & Cat. A & 0.008 & 98 \\
\hline 10 & Cat. A & 0.004 & 76 \\
\hline 11 & Cat. A & 0.002 & 57 \\
\hline 12 & Cat. A & 0.001 & 37 \\
\hline 13 & Cat. A & 0.0005 & 32 \\
\hline 14 & Cat. A & 0.0002 & 9 \\
\hline 15 & $\mathrm{PdCl}_{2}$ & 0.008 & 49 \\
\hline 16 & $\mathrm{Pd}(\mathrm{OAc})_{2}$ & 0.008 & 20 \\
\hline 17 & $\mathrm{PdCl}_{2}\left(\mathrm{PPh}_{3}\right)_{2}$ & 0.008 & 15 \\
\hline 18 & $\mathrm{Pd}\left(\mathrm{PPh}_{3}\right)_{4}$ & 0.008 & 3 \\
\hline
\end{tabular}

${ }^{a}$ Reaction Conditions: 1 a $(0.20 \mathrm{mmol}), \mathbf{2 a}(0.40 \mathrm{mmol})$, Pd-catalyst, water $(2 \mathrm{~mL})$, $30{ }^{\circ} \mathrm{C}, 8$ h. ${ }^{\mathrm{b}} \mathrm{GC}$ yield. 
Table 4 Optimization of the Reaction Conditions ${ }^{\mathrm{a}}$

\begin{tabular}{|c|c|c|c|c|c|}
\hline Entry & $\begin{array}{c}\text { Cat. A } \\
\text { (mol \%) }\end{array}$ & $\begin{array}{c}\mathrm{NaB}(\mathrm{Ph})_{4} \\
(\mathrm{mmol})\end{array}$ & $\begin{array}{c}T \\
\left({ }^{\circ} \mathrm{C}\right)\end{array}$ & $\begin{array}{c}\text { Time } \\
\text { (h) }\end{array}$ & $\begin{array}{c}\text { 3a yield } \\
\text { [\%] }\end{array}$ \\
\hline \multicolumn{6}{|c|}{ Effect of time } \\
\hline 1 & 0.008 & 0.40 & 30 & 2 & 61 \\
\hline 2 & 0.008 & 0.40 & 30 & 4 & 78 \\
\hline 3 & 0.008 & 0.40 & 30 & 6 & 86 \\
\hline 4 & 0.008 & 0.40 & 30 & 8 & 98 \\
\hline 5 & 0.008 & 0.40 & 30 & 10 & 98 \\
\hline
\end{tabular}

Effect of $\mathrm{NaBPh}_{4}$ stoichiometry

$\begin{array}{ccc}6 & 0.008 & 0.40 \\ 7 & 0.008 & 0.30 \\ 8 & 0.008 & 0.20 \\ 9 & 0.008 & 0.10 \\ 10 & 0.008 & 0.05\end{array}$

\section{Effect of temperature}

$\begin{array}{lcc}11 & 0.008 & 0.40 \\ 12 & 0.004 & 0.40 \\ 13 & 0.002 & 0.40 \\ 14 & 0.001 & 0.40 \\ 15 & 0.0005 & 0.40 \\ 16 & 0.008 & 0.40 \\ 17 & 0.004 & 0.40 \\ 18 & 0.002 & 0.40 \\ 19 & 0.001 & 0.40 \\ 20 & 0.0005 & 0.40 \\ 21 & 0.0005 & 0.40\end{array}$

$\begin{array}{lll}30 & 8 & 98 \\ 30 & 8 & 89 \\ 30 & 8 & 76 \\ 30 & 8 & 68 \\ 30 & 8 & 43\end{array}$

$\begin{array}{lll}40-98 & 98\end{array}$

40

40

40

40

50

50

50

50

50

50

8
8
8
8
8
8
8
8
8
8
16

98

98

84

58

52

98

98

97

80

68

93
${ }^{a}$ Reaction Conditions: 1a $(0.20 \mathrm{mmol}), \mathbf{2 a}$, Cat. A, water $(2 \mathrm{~mL}) .{ }^{\mathrm{b}} \mathrm{GC}$ yield.

Therefore, the catalyst activity of all palladium catalysts was again compared under the same reaction conditions at 0.008 mol \% catalyst loading to select the best palladium catalyst (Table 3, entries 9, 15-18). It was observed that among all the screened palladium catalysts, Cat. A gave the highest yield of 3a up to $98 \%$ (Table 3, entry 9) while only moderate yields up to $49 \%$ were obtained with $\mathrm{PdCl}_{2}$ (Table 3, entry 15). Interestingly with $\mathrm{PdCl}_{2}\left(\mathrm{PPh}_{3}\right)_{2}$ and $\mathrm{Pd}(\mathrm{OAc})_{2}$ lower yields $20 \%$ and $15 \%$ respectively of $\mathbf{3 a}$ were obtained (Table 3 , entries 16 and 17) and with $\mathrm{Pd}\left(\mathrm{PPh}_{3}\right)_{4}$ the lowest yield 9\% of $\mathbf{3 a}$ was obtained (Table 3 , entry 18 ). Therefore, our catalyst screening study confirms the superiority of Cat. A over the screened catalysts. Subsequently a detailed optimization study was done for Cat. A catalyzing allylic arylation of cinnamyl acetate with sodium tetraphenylborate under aqueous conditions. For optimization of our protocol we firstly performed a time study (Table 4, entries 1-5) and it was observed that after 8 hours $98 \%$ yield of product $3 a$ was obtained (Table 4 , entry 4 ). Then we checked the influence of stoichiometric ratio of sodium tetraphenylborate on yield of 3a (Table 4, entries 6-10) and we observed that $98 \%$ yield of 3 a was obtained with two equivalence of sodium tetraphenylborate (Table 4, entry 6). However, further lowering the amount of sodium tetraphenylborate results in lower yield of $\mathbf{3 a}$ (Table 4, entries 7-10). Finally, the influence of temperature was checked and reactions were carried out at $40^{\circ} \mathrm{C}$ (Table 4, entries 11-15) and $50{ }^{\circ} \mathrm{C}$ (Table 4 , entries $16-21$ ) by varying catalyst loadings of
Table 5 Substrate Scope Study

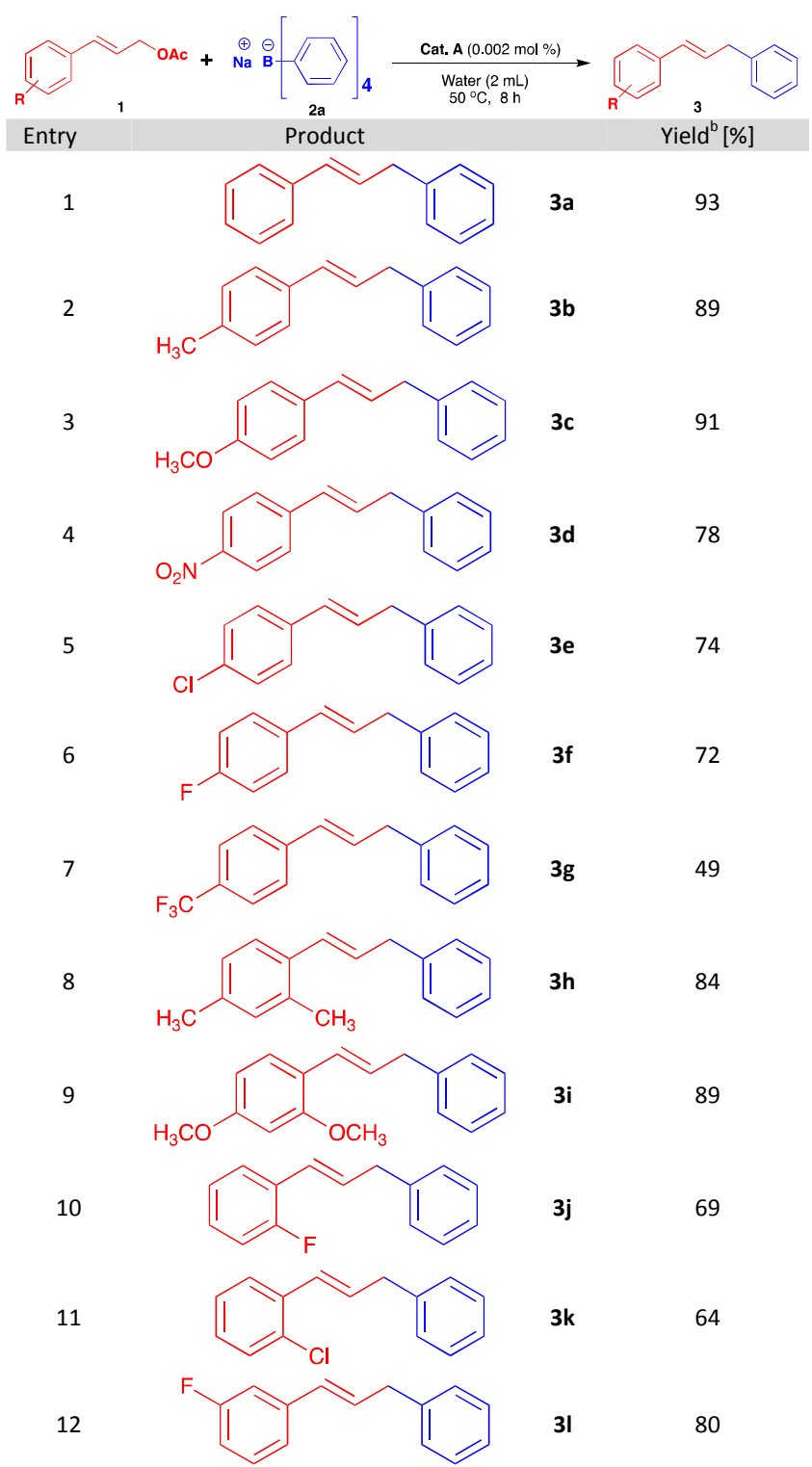

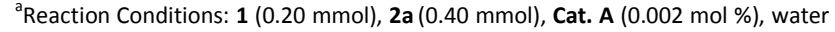
$(2 \mathrm{~mL}), 50^{\circ} \mathrm{C}, 8$ h. ${ }^{\mathrm{b}} \mathrm{NMR}$ Yield.

Cat. A from $0.008 \mathrm{~mol} \%$ to $0.0005 \mathrm{~mol} \%$. Interestingly with increasing temperature up to $50{ }^{\circ} \mathrm{C}$ higher yields up to $97 \%$ of 3a were obtained, notably with lower catalyst loading of 0.002 mol \% of Cat. A (Table 4, entry 18). Remarkably $68 \%$ yield of $3 a$ was obtained with $0.0005 \mathrm{~mol} \%$ of Cat. A within 8 hours (Table 4, entry 20) which is further improved to $93 \%$ by extending reaction time to 16 hours (Table 4, entry 21). Our study confirms that either by increasing the reaction temperature or by extending the reaction time further lowering of catalyst loading is possible to still achieve high yields of 3a. However, considering the time as limiting factor to achieve higher yields in short time the next substrate scope study was explored at $50{ }^{\circ} \mathrm{C}$ with $0.002 \mathrm{~mol} \%$ of Cat. A. 
Thereupon as results from our optimization study on allylic arylation, our final optimized reaction conditions are cinnamyl acetate (1a, $0.20 \mathrm{mmol})$, sodium tetraphenylborate $(2 \mathrm{a}, 0.40$ $\mathrm{mmol})$, Cat. A (0.002 mol \%) in water $(2 \mathrm{~mL})$ at $50{ }^{\circ} \mathrm{C}$ for 8 hours under air atmosphere. Using this optimized reaction conditions the substrate scope was checked for various cinnamyl acetate derivatives (Table 5). First cinnamyl acetates bearing electron-donating groups such as $(E)-3-(p$-tolyl)allyl acetate (1b) and (E)-3-(4-methoxyphenyl)allyl acetate (1c) were screened which resulted in excellent yield of corresponding arylated product $\mathbf{3 b}$ and $\mathbf{3} \mathbf{c}$ up to $89 \%$ and $91 \%$ respectively (Table 5 , entries 2 and 3 ). Effects of electron withdrawing (E)-3-(4-nitrophenyl)allyl acetate (1d) were studied and moderate yield up to $78 \%$ of $\mathbf{3 d}$ were obtained (Table 5, entry 4). It was observed that $p$-halo substituted cinnamyl acetates such as (E)-3-(4-chlorophenyl)allyl acetate (1e) and (E)-3-(4-fluorophenyl)allyl acetate (1f) also reacted smoothly and $74 \%$ yield of $\mathbf{3 e}$ and $72 \%$ yield of $\mathbf{3 f}$ were obtained (Table 5, entries 5 and 6 ). However, lower yield $49 \%$ of $\mathbf{3 g}$ were obtained with $(E)$-3-(4-(trifluoromethyl)phenyl)allyl acetate (1g) (Table 5, entry 7). Next we checked the effect of sterically hindered ortho and meta disubstituted derivatives of cinammyl acetates such as (E)-3-(2,4-dimethylphenyl)allyl acetate (1h) and (E)-3-(2,4-dimethoxyphenyl)allyl acetate (1i) interestingly higher yields of $\mathbf{3 h}$ and $\mathbf{3 i}$ up to $84 \%$ and $89 \%$ respectively were obtained (Table 5 , entries 8 and 9). Moreover, ortho substituted cinnamyl acetates such as (E)-3(2-fluorophenyl)allyl acetate (1j) and (E)-3-(2chlorophenyl)allyl acetate (1k) also reacted efficiently and arylated products $\mathbf{3} \mathbf{j}$ and $\mathbf{3 k}$ obtained in $69 \%$ and $64 \%$ yield (Table 5, entries 10 and 11). Likewise with (E)-3-(3fluorophenyl)allyl acetate (1) up to $80 \%$ yield of $\mathbf{3 l}$ were obtained (Table 5, entry 12). Therefore, overall substrate scope study confirms the wide applicability of our protocol. Its noteworthy to mention that in all cases traces of biphenyl side product formed.

\section{Proposed Mechanism:}

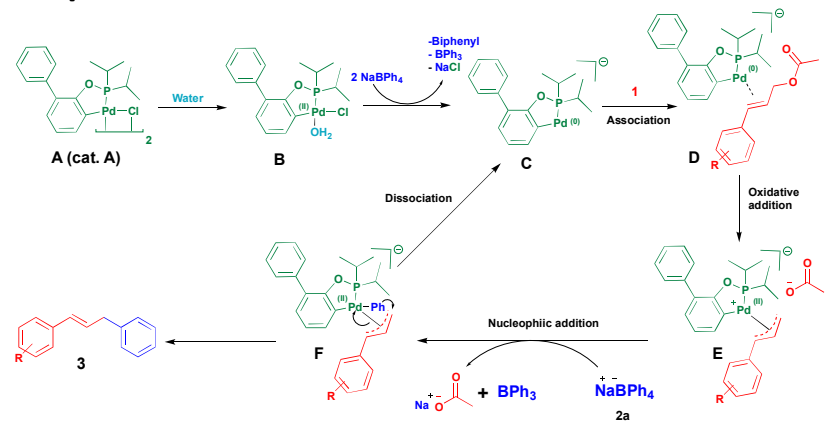

Scheme 2 Proposed mechanism

The Cat. A is dimer (A) and as soon as water is added the Cat. A dimer breaks down and form Pd (II) intermediate (B) (Scheme 2). It should be noted that because of bulky isopropyl substituent the phosphorous center is rich in electron density and well shielded against cleavage by nucleophilic attack on phosphorus favoring oxidative addition of the $\mathrm{NaBPh}_{4}$ and a well-balanced steric bulk stabilizes the palladacyclic motive. Hence, we suggest that addition of $\mathrm{NaBPh}_{4}$ induces first a double transmetallation of phenyl groups, followed by a reductive elimination of biphenyl resulting in an undercoordinated, palladacyclic anionic $\operatorname{Pd}(0)$ species (C). Our previous mechanistic study on Suzuki coupling ${ }^{14}$ and in current study the formation of traces of biphenyl as side product support the formation of intermediate $\mathbf{B}$ and $\mathbf{C}$. In next step the palladium coordinates to the alkene bond of $\mathbf{1}$, forming a $\eta 2 \pi$-allyl-Pd(0) complex (D). Subsequently oxidative addition of palladium occurs in which the leaving group acetate is expelled result in forming intermediate a $\eta 3 \pi$-allyl-Pd(II) complex (E). In next step the phenyl nucleophile formed by transmetallation from $\mathrm{NaBPh}_{4}$ adds to the allyl group (F) result in formation of product 3a. After the completion of the reaction, the palladium detaches from the product $\mathbf{3 a}$ and forming again Pd (0) intermediate (C) and catalytic cycle starts again.

\section{Conclusions}

In conclusion, a greener aqueous protocol for allylic arylation of cinnamyl acetates with sodium tetraphenylborate using $0.002 \mathrm{~mol} \%$ of Bedford-type palladacycle catalyst is reported. All reactions proceed efficiently at mild reaction conditions in water under air atmosphere within a short reaction time of 8 hours. All corresponding products are obtained in excellent yields up to $93 \%$. In addition, we also confirmed that further lowering of catalyst loading under aqueous condition is possible by increasing temperature or time as with $0.0005 \mathrm{~mol}$ $\%$ of Bedford-type palladacycle catalyst almost $93 \%$ product was obtained.

\section{Conflicts of interest}

There are no conflicts to declare.

\section{Acknowledgements}

The author Seema Arun Ghorpade is thankful to the Institute of Chemical Technology, Matunga, Mumbai and Department of Science and Technology (DST) India for providing DST INSPIRE Senior Research Fellowship (IF110631). This work was supported by the King Abdullah University of Science and Technology (KAUST baseline funding and GCR grant FIC/2010/07). Authors are gratefully acknowledging support from King Abdullah University of Science and Technology (KAUST), Saudi Arabia.

\section{Notes and references}

1 (a) J. Tsuji, H. Takahashi and M. Morikawa, Tetrahedron Lett., 1965, 6, 4387; (b) B. M. Trost, and M. L. Crawley, Chem. Rev., 2003, 103, 2921; (c) J. Muzart, Tetrahedron, 2005, 61, 4179; (d) L. Milhau and P. Guiry, J. Top. Organomet. Chem., 2011, 38, 95; (e) N. A. Butt and W. Zhang, Chem. Soc. Rev., 2015, 
44, 7929; (f) R. K. Sharma, S. Sharma, S. Dutta, R. Zobril and M. B. Gwanade, Green Chem., 2015, 17, 3207; (g) A. K. Rathi, M. B. Gawande, R. Zboril and R. S. Varma, Coord. Chem. Rev., 2015, 291, 68.

2 (a) J. Tsuji, Acc. Chem. Res., 1969, 2, 144; (b) B. M. Trost, Angew. Chem. Int. Ed., 1989, 28, 1173; (c) Trost, B. M. Acc. Chem. Res., 1996, 29, 355; (d) B. Sundararaju, M. Achard and C. Bruneau, Chem. Soc. Rev., 2012, 41, 4467; (e) S. Oliver and P. A. Evans, Synthesis, 2013, 3179.

3 (a) J. Muzart, Eur. J. Org. Chem., 2007, 3077; (b) A. M. Johns, Z. Liu and J. F. Hartwig, Angew. Chem. Int. Ed., 2007, 46, 7259; (c) Y. S. Wagh, P. J. Tambade, D. N. Sawant and B. M. Bhanage, Eur. J. Org. Chem., 2010, 26, 5071; (d) Y. S. Wagh, D. N. Sawant, P. J. Tambade, K. P. Dhake, and B. M. Bhanage, Tetrahedron, 2011, 67, 2414; (e) Y. S. Wagh, D. N. Sawant, K. P. Dhake and B. M. Bhanage, Catal. Sci. Technol., 2012, 2, 835; (f) B. R. Vaddula, A. Saha, R. S. Varma, and J. Leazer, Eur. J. Org. Chem., 2012, 6707; (g) M. Rueping, C. Vila and U. Uria, Org. Lett., 2012, 14, 768; (h) D. Krishnan, M. Wu, M. Chiang, Y. Li, P. -H. Leung and S. A. Pullarkat, Organometallics, 2013, 32, 2389; (i) R. B. N. Baig, B. R. Vaddula, M. A. Gonzaleza and R. S. Varma, RSC Adv., 2014, 4, 9103; (j) J. Jing, X. Huo, J. Shen, J. Fu, Q. Meng and W. Zhang, Chem. Commun., 2017, 53, 5151 .

4 (a) C. Chevrin, J. Le Bras, F. Henin, J. Muzart, A. PlaQuintana, A. Roglans and R. Pleixats, Organometallics, 2004, 23, 4796; (b) M. Rueping, B. J. Nachtsheim and A. Kuenkel, Org. Lett., 2007, 9, 825; (c) B. M. Trost and M. L. Crawley, Top. Organomet. Chem., 2012, 38, 321; (d) Y. Hong and B. M. Stoltz, Eur. J. Org. Chem., 2013, 2745; (e) B. M. Trost, Tetrahedron, 2015, 71, 5708; (f) Q. Jinlong and J. Gaoxi, Current Catalysis, 2017, 6, 25; (g) Y. -L. Lai and J. -M. Huang, Org. Lett. 2017, 19, 2022.

5 (a) T. Mino, T. Kogure, T. Abe, T. Koizumi, T. Fujita and M. Sakamoto, Eur. J. Org. Chem., 2013, 1501; (b) K. Watanabe, T. Mino, T. Abe, T. Kogure and M. Sakamoto, J. Org. Chem., 2014, 79, 6695; (c) Y. Lee, S. Shabbir, S. Lee. H. Ahn and H. Rhee, Green Chem., 2015, 17, 3579; (d) S. Y. Lee and J. F. Hartwig, J. Am. Chem. Soc., 2016, 138, 15278.

6 (a) B. M. Trost and F. D. Toste, J. Am. Chem. Soc., 1998, 120, 815; (b) B. Schmidt and S. Nave, Adv. Synth. Catal., 2006, 348, 531; (c) S. F. Kirsch, L. E. Overman and N. S. White, Org. Lett., 2007, 9, 911; (d) Y. S. Wagh, D. N. Sawant, K. P. Dhake, K. M. Deshmukh and B. M. Bhanage, Tetrahedron Lett., 2011, 52, 5676; (e) A. Saha, J. Leazer and R. S. Varma, Green Chem., 2012, 14, 67; (f) R. B. N. Baig and R. S. Varma, Ind. Eng. Chem. Res., 2014, 53, 18625; (g) U. Uria, C. Vila, M. -Y. Lin and M. Rueping, Chem. Eur. J., 2014, 20, 13913; (h) M. Halder, M. M. Islam, S. Ahammed and S. M. Islam, RSC Adv., 2016, 6, 8282; (i) C. A. Discolo, A. G. Graves and D. R. Deardorff, J. Org. Chem., 2017, 82, 1034.

7 (a) Y. C. Jung, R. K. Mishra, C. H. Yoon and K. W. Jung, Org. Lett., 2003, 5, 2231; (b) F. M. A. Bar, M. A. Khanfar, A. Y. Elnagar, F. A. Badria, A. M. Zaghloul, K. F. Ahmad, P. W. Sylvester and K. A. El Sayed, Bioorg. Med. Chem., 2010, 18, 496.

8 (a) L. Botella and C. J. Najera, Organomet. Chem., 2002, 663, 46; (b) H. Ohmiya, Y. Makida, T. Tanaka and M. Sawamura, J. Am. Chem. Soc., 2008, 130, 17276; (c) Y. M. A. Yamada, T. Watanabe, K. Torii and Y. Uozumi, Chem. Commun., 2009, 5594; (d) H. Ohmiya, Y. Makida, D. Li, M. Tanabe and M. Sawamura, J. Am. Chem. Soc., 2010, 132, 879; (e) F. C. Pigge, Synthesis, 2010, 11, 1745; (f) D. Li, T. Tanaka, H. Ohmiya and M. Sawamura, Org. Lett., 2010, 12, 3344. (g) Y. Junga and I. Kim, Org. Biomol. Chem., 2015, 13, 4331.

9 (a) E. Blart, J. P. Genet, M. Safi, M. Savignac and D. Sinou, Tetrahedron, 1994, 50, 505; (b) Z. Dong and Z. Ye, Adv. Synth. Catal., 2014, 356, 3401; (c) C. Najera, J. Gil-Molto, S.
Karlstrçma, Adv. Synth. Catal.; 2004, 346, 1798; (d) Z. Dong and Z. Ye, Applied Catalysis, A: General, 2015, 489, 61; (e) Y. M. A. Yamada, Chem. Pharm. Bull., 2017, 65, 805.

10 (a) H. Tsukamoto, T. Uchiyama, T. Suzuki and Y. Kondo, Org. Biomol. Chem., 2008, 6, 3005; (b) H. Ohmiya, Y. Makida, D. Li, T. Tanaka and M. Sawamura, J. Am. Chem. Soc., 2010, 132, 879; (c) B. Yao, Y. Liu, M. -D. Wang, J. -H. Li, R. -Y. Tang, X. -G. Zhang and C. -L. Deng, Adv. Synth. Catal., 2012, 354, 1069; (d) C. Li, J. Xing, J. Zhao, P. Huynh, W. Zhang, P. Jiang and Y. J. Zhang, Org. Lett., 2012, 14, 390; (e) J. Zhao, J. Ye and Y. J. Zhang, Adv. Synth. Catal., 2013, 355, 491; (f) J. Ye, J. Zhao, J. Xu, Y. Mao and Y. J. Zhang, Chem. Commun., 2013, 49, 9761; (g) H. -B. Wu, X. -T. Ma and S. -K. Tian, Chem. Commun., 2014, 50, 219

11 (a) Y. Uozumi, H. Danjo and T. Hayashi, J. Org. Chem., 1999, 64, 3384; (b) S. M. Sarkar, Y. Uozumi and Y. M. A. Yamada, Angew. Chem. Int. Ed., 2011, 50, 9437; (c) Y. M. A. Yamada, S. M. Sarkar and Y. J. Uozumi, Am. Chem. Soc., 2012, 134, 3190; (d) G. Hamasaka, F. Sakurai and Y. Uozumi, Chem. Comm., 2015, 51, 3886; (e) G. Hamasaka, F. Sakurai and Y. Uozumi, Tetrahedron, 2015, 71, 6437.

12 (a) A. Zapf and M. Beller, Topics in Catalysis, 2002, 19, 101; (b) H. -S. Blaser, A. Indolese, F. Naud, U. Nettekoven and A. Schnyder, Adv. Synth. Catal., 2004, 346, 1583; (c) C. Torborg and M. Beller, Adv. Synth. Catal., 2009, 351, 3027.

13 (a) R. B. Bedford and S. L. Welch, Chem. Commun., 2001, 129; (b) R. B. Bedford, S. L. Hazelwood and M. E. Limmert, Chem. Commun., 2002, 2610; (c) R. B. Bedford, C. S. J. Cazin and S. L. Hazelwood, Angew. Chem., Int. Ed., 2002, 41, 4120; (d) R. B. Bedford, S. L. Hazelwood, P. N. Horton and M. B. Hursthouse, Dalton Trans., 2003, 4164; (e) R. B. Bedford and M. E. Blake, Adv. Synth. Catal., 2003, 345, 1107; (f) R. B. Bedford, Chem. Commun., 2003, 1787.

14 (a) A. N. Marziale, Stefan H. Faul, T. Reiner, S. Schneider and J. Eppinger, Green Chem., 2010, 12, 35; (b) A. N. Marziale, D. Jantke, S. H. Faul, T. Reiner, E. Herdtweck and J. Eppinger, Green Chem., 2011, 13, 169; (c) A. Zernickel, W. Du, S. A. Ghorpade, D. N. Sawant, A. Makki, N. Sekar and J. Eppinger, J. Org. Chem., 2018, 83, 1842.

15 (a) D. N. Sawant, Y. S. Wagh, K. D. Bhatte and B. M. Bhanage, J. Org. Chem., 2011, 76, 5489; (b) D. N. Sawant, Y. S. Wagh, P. J. Tambade, K. D. Bhatte and B. M. Bhanage, Adv. Synth. Catal., 2011, 353, 781; (c) V. S. Patil, V. S. Padalkar, A. S. Chaudhari and N. Sekar, Catal. Sci. Technol., 2012, 2, 1681; (d) A. S. Chaudhari, Y. S. Parab, V. Patil, N. Sekar and S. R. Shukla, RSC Adv., 2012, 2, 12112; (e) S. G. Ghorpade, D. N. Sawant, A. Makki, N. Sekar and J. Eppinger, Green Chem., 2018, 20, 425. 


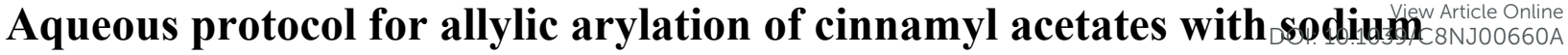 tetraphenylborate using Bedford-type palladacycle catalyst
}

\author{
Seema Arun Ghorpade ${ }^{a, b}$, Dinesh Nanaji Sawant*a, Dominik Renn ${ }^{a}$, Anna Zernickel $^{\mathrm{a}}$, \\ Weiyuan Du ${ }^{\mathrm{a}}$, Nagaiyan Sekar*b and Jörg Eppinger* ${ }^{\mathrm{a}}$
}

\begin{abstract}
${ }^{a}$ King Abdullah University of Science and Technology, Division of Physical Sciences \& Engineering, KAUST Catalysis Center (KCC), Thuwal 23955-6900, Saudi Arabia.

E-mail:jorg.eppinger@kaust.edu.sa,dinesh1.sawant@gmail.com

${ }^{b}$ Department of Dyestuff Technology, Institute of Chemical Technology (Deemed University), N. Parekh Marg, Matunga, Mumbai-400019, Maharashtra, India.

E-mail:n.sekar@ictmumbai.edu.in
\end{abstract}

\section{TOC}

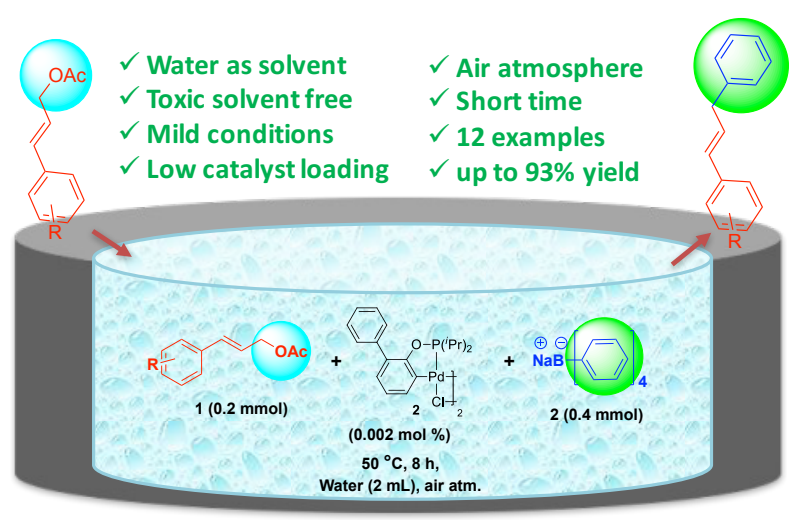

Allylic arylation using $0.002 \mathrm{~mol} \%$ of Bedford-type palladacycle catalyst is described under mild reaction conditions. 